\title{
Justicia poética en las dos américas: Walt Whitman y Rubén Darío1
}

\author{
Poetic justice in both americas: \\ Walt Withman and Rubén Darío \\ Manuel de J. Jiménez Moreno \\ Facultad de Derecho \\ Universidad Nacional Autónoma de México-MÉXICO \\ mjimenezm2@derecho.unam.mx
}

\section{Resumen}

En este artículo pueden ser encontradas dos consideraciones en torno a la noción de justicia y al tratamiento que se ha dado de ella en los estudios de Derecho y Literatura. El fin que se persigue es brindar una visión alterna de las posturas anglosajonas, enfocado en el potencial decolonial de la Literatura como instrumento de aproximación al Derecho. En ese sentido, el sustrato literario de esta discusión, compuesto por los trabajos poéticos de Whitman y Darío, proporcionan una visión contrapuesta de la justicia poética. En ese orden de ideas, la perspectiva inicial de este trabajo se da a través de un contraste entre la América sajona y la latina, lo que sirve de impulso para esbozar la complejidad de la conceptualización de justicia.

Palabras clave: dos Américas; John Rawls; Justicia poética; Ruben Darío; Walt Withman.

\begin{abstract}
In this paper two considerations can be found around the notion of justice and the treatment that has been given of it in the studies of Law and Literature. The aim is to provide an alternative vision of Anglo-Saxon positions, focused on the decolonial potential of Literature as an instrument of approach to Law. In this sense, the literary substratum of this discussion, composed of the poetic works of Whitman and Darío, provides a contrasting vision of poetic justice. In that order of ideas, the initial perspective of this work is contrast between Saxon and Latin America can be noticed, which serves as an impetus to outline the complexity of the conceptualization of justice
\end{abstract}

Key words: Both Americas; John Rawls; Poetic justice; Rubén Darío; Walt Whitman. 


\section{A modo de advertencia poemática}

De acuerdo con los estudios tradicionales de tópica literaria y después con los de Derecho y Literatura (DyL), la «justicia poética» es un locus retórico que culmina con la siguiente fórmula: la bondad y la virtud triunfan, mientras que la maldad es castigada con una condena inapelable. Después de que se desarrolla la tensión dramática, los vericuetos y la peripecia, el universo coloca en su sitio a cada uno de los personajes con premios y sanciones. Se trata de una técnica narrativa emparentada y actualizada con el happy ending. Aunque esta modalidad de justicia poética puede aparecer en las siguientes líneas, esta idea puede extenderse y cambiar en este ensayo, pues el concepto es amplio y robusto en la historia occidental. En este sentido, la propuesta que Martha Nussbaum desarrolló en su libro Poetic Justice, publicado en 1995 por la Beacon Press en Boston ${ }^{2}$, constituye un punto de partida para el universo anglosajón que poco abona a la tradición retórica del tópico de la justicia poética y al contexto hispanoamericano.

De hecho, este texto busca abrir otra senda diferente a justicia poética nussbaniana que sea más cercana a nuestra tradición latinoamericana y con el fin de decolonizar parcialmente la idea de «justicia poética» en la teoría de la justicia y la filosofía moral. Para ello, no sólo se estudia la poética de Rubén Darío, sino que se ofrece otra lectura de Walt Whitman, poeta citado por la profesora estadounidense en Poetic Justice. En un sentido natural, la justicia poética será simplemente el dictum de los poetas, no siempre grata al escrutinio de un filósofo analítico o a los ojos de un iuspositivista de corte ideológico. A continuación se muestran ejemplos sobre cómo dos poetas torales en la literatura universal atisban y ejercen la justicia en sus entornos inmediatos, teniendo como referencia una teoría y praxis de la justica. La elección de Darío y Whitman busca generar un contrapunto entre la visión letrada del siglo XIX, tanto en el norte y el sur, apelar al ámbito cultural que marca el poeta colombiano José María Torres Caicedo en su famoso poema "Las dos Américas": diferenciar la América anglosajona y la América Latina ${ }^{3}$.

Pero antes de entrar a los análisis en cuestión, hay que considerar que el poeta de Metapa era un lector entusiasta del norteamericano, en sus memorias, dice que Alejandro Sawa "Encontró sobre mi mesa unos cuantos libros, entre ellos un Walt Whitman, que no conocía. Se puso a hojear una edición guatemalteca de mi Azul, en que, por mal de mis pecados, incluí unos versos franceses, entre los cuales los hay que no son versos, pues yo ignoraba cuando los escribí muchas nociones de poética francesa" (Darío, 2015a: 102). Darío hace gala de su "galicismo mental», que le fue reprochado en la famosa carta de Valera, y reconoce conscientemente sus apegos coloniales. La escritura whitmaniana será un parangón en la formación de su poética, pues en la segunda edición de Azul... aparece en la sección de "Medallones" 4 el poema "III. Walt Whitman", probablemente escrito en 18905:

En su país de hierro vive el gran viejo, bello como un patriarca, sereno y santo. Tiene en la arruga olímpica de su entrecejo algo que impera y vence con noble encanto. 
Su alma del infinito parece espejo; son sus cansados hombros dignos del manto; y con arpa labrada de un roble añejo como un profeta nuevo canta su canto.

Sacerdote, que alienta soplo divino, anuncia en el futuro, tiempo mejor. Dice el águila: «iVuela!», «iBoga!», al marino,

$\mathrm{y}$ «iTrabaja!», al robusto trabajador. ¡Así va ese poeta por su camino con su soberbio rostro de emperador! (Darío, 2011a: 183)

\section{Whitman: la Justicia regresa después de la guerra}

La vida y obra del poeta Walt Whitman (18191892) son fundacionales en la construcción de la nación norteamericana. Whitman, en muchos sentidos, afianzó los valores del liberalismo y la democracia representativa que unificaron a los estados en una Unión. Se puede afirmar que se trata del poeta nacional por excelencia e incluso el poeta continental de mayores alcances. Tanto Rubén Darío, León Felipe y Jorge Luis Borges consideran su obra como uno de las fuerzas primigenias en la poesía moderna junto con los parnasianos y simbolistas franceses ${ }^{6}$. Para Ralph Waldo Emerson, contemporáneo del poeta y considerado una autoridad literaria de su tiempo, la escritura del newyorkino representaba un nuevo horizonte cuya lectura implicaba una toma de postura ético-estética. "Emerson tenía miedo de las alarmantes cosas que quería poner Walt en aquella nueva edición. Hablaba demasiado abiertamente de las cosas que la mayoría de la gente había convenido en no mencionar. No era sólo que escribiera una extraña mezcla de verso y prosa. Su tema era inusitado. Su lenguaje era extraordinariamente fuerte. Seguramente sus lectores lo malinterpretarían" (Deutsch, 1992a: 92).

Más allá de escribir una apología whitmaniana o hacer un estudio estilístico de sus poemas y marcar una genealogía con su descendencia poética; lo que nos interesa rastrear en sus poemas es su ideal de justicia, teniendo como presupuesto el concepto de libertad que fue el principal debate de su época. Recordemos que la vida del poeta quedó atravesada por la Guerra Civil. Él, un abolicionista con gran sensibilidad editó en 1848 un semanario llamado Freeman donde puntualizó su opinión sobre los acontecimientos públicos. Durante la batalla, apoyó la causa no desde las armas sino como enfermero atento y servicial. De este modo, Walt Whitman puede ser apreciado como un reformador no sólo de la poesía, sino de la moral decimonónica anglosajona. El poeta se mantuvo con una conciencia abierta: se negaba a reconocer el trato de clases y consideraba la bondad humana como eje transformador de la civilización. Trabó amistad lo mismo con tenderos y marineros, que con políticos y letrados. Al final se trata de una personalidad que considera los valores extremos del liberalismo, de la autonomía de la voluntad como un principio preeminente y que -al igual que John Stuart Mill- apuesta por la personalidad excéntrica y la singularidad incluso a costa del rechazo social7.

La preocupaciónn de Whitman además de promover una vehemente libertad en los quehaceres diarios fue organizar líricamente un proyecto de 
nación donde cada uno de los miembros de la comunidad política coadyuvaran en la narración de una épica común. La sustanciación de la justicia, que no necesariamente es social, deliberativa o conmutativa, se ofrece en un sentido metapoético. A través de la palabra, el territorio de la idealizada nación comienza en su natal Long Island y rebasa los estados de la Unión americana, fundiéndose con los elementos de la naturaleza y el cosmos. La poesía genera aquí un efecto de expansión donde la moralidad y la política pueden trastocarse con una semántica indeterminada: los derechos ya no son nuestros derechos, la guerra ya no es la guerra. Cada uno de los elementos devienen en un patrimonio místico e integran el sentir de los hombres comunes, de las mujeres y familias que conforman ese Estado poético-político. De allí que Whitman se oponga a la clase aristocrática que frena con sus prejuicios la ansiada comunión.

La política de partido en esa época le disgustaba totalmente, y con razón. “¿Van los partidosa usurpar por siempre el gobierno?" exclamó Walt, en un furioso discurso que no llegó a imprimirse. "¿Van los abogados, los caras de masa y los trecientos cincuenta mil propietarios de esclavos a absolver toda la preeminencia de treinta millones? ¿Dónde estála verdadera Norteamérica? ¿Dónde están los labriegos, los campesinos, los hombres con hachas, con palas, con hoces y mayales? ¿Dónde están los carpinteros, los albañiles, los mecánicos, los conductores de caballos, los trabajadores de fábricas? ¿Dónde está el espíritu de hombría y sentido común de estos Estados? (Deutsch, 1992b: 86).
Como ya se dijo con anterioridad, la idea de libertad es esencial tanto para el Whitman periodista como para el Whitman poeta. La búsqueda de la libertad pero, sobre todo, su buen ejercicio es una de sus preocupaciones expresivas, llevándolo a reflexionar sobre su participación dentro de la Guerra de Secesión y el señalamiento de lo que él consideraba los vicios de la sociedad norteamericana. En esta ocasión, para entender la noción whitmaniana de libertad hay que entender sus convicciones abolicionistas, como periodista o redactor.

Para él, la cuestión de los afroamericanos era delicada y debe tomarse con ciertas reservas. Por ello es necesario que los esclavos se emancipen, pero eso no significa que su condición mejore considerablemente en relación con los blancos. Whitman "Estaba dispuesto a conceder que los negros podrían estar mejor en una plantación norteamericana que en las selvas de África; pero no podía tener tráfico con los hombres responsables de los horrores del comercio de esclavos. Donde la libertad no sacaba la sangre de la esclavitud, allí la esclavitud sacaba la sangre de la libertad" (Deutsch, 1992c: 86). El slave quizás aún no estaba totalmente preparado para ejercer su libertad plena. El poeta cree que es mejor estar bajo la tutela de buenos amos que padecer infortunios pero, de ningún modo, admitió la reducción de un ser humano a una res susceptible de ser intercambiada por dinero. La libertad del esclavo entonces se encuentra supeditada a ciertas circunstancias externas más allá del ánimo interno del sujeto: es una libertad negativa. 
Por otro lado, también está el Walt Whitman poeta, quien abraza en muchos sentidos el concepto positivo de libertad. Éste, de acuerdo con Isaiah Berlin (2001a: 60), deriva del deseo del individuo de ser su propio amo y no circunscribir sus acciones a agentes externos. Se trata de una libertad ontológica, de "la metáfora de ser amo de uno mismo que, quizás, en origen era inofensiva. «Soy mi propio amo»; «no soy esclavo de ningún hombre»”. Esta libertad es patente en Song of Myself y otros poemas: "Let others finish specimens, I never finish specimens,/ I start them by exhaustless laws as Nature does, fresh and modern continually./ I give nothing as duties, / What others give as duties I give as living impulses, / (Shall I give the heart's action as a duty?)" (Whitman, 2003a: 40).8 Dentro de la obra de poeta, la libertad -como concepto, valor e imagen- aparece de forma intermitente. En unas ocasiones, el tratamiento retórico que el poeta le otorga es metagógica: Libertad viene y va, se muda entre las sociedades temporales: "And you, Libertad of the world!/ You shall sit in the middle well-pois'd thousands and thousands of years, / As today, from one side the nobles of Asia, the Princes of Asia come to you,/ As tomorrow, from the other side, the queen of England sends her eldest son to you" (Whitman, 2003b: 56).

En el poema subsiste un tono profético. Se sabe que Libertad, hoy joven, tomará a la postre su asiento con gallardía y señorío en el centro del mundo. Por su parte, los Estados restantes esperarán ese momento de realización. El método es sencillo: hay que emular la pauta liberal y democrática de los Estados Unidos para consagrarse como nación civilizada y creer fervientemente en el progreso. Esta es una proyección idílica de Whitman. No obstante, en otro poema, agobiado por las consecuencias de la guerra, pide a Libertad que vuelva: que regrese a América después de inventariar las pérdidas.

Turn O Libertad, for the war is over, From it and all henceforth expanding, doubting no more, resolute, sweeping the world, Turn from lands retrospective recording proofs of the past,

From the singers that sing the trailing glories of the past,

From the chants of the feudal world, the triumphs of kings, slavery, caste,

Turn to the world, the triumphs reserv'd and to come -give up that backward world. (Whitman, 2003c: 226).

En la visión whitmaniana, Libertad se queda arraigada en los Estados Unidos por largo tiempo, una vez que en 1865 el conflicto concluye y queda prohibida la esclavitud de los estados sureños ${ }^{9}$. En relación con otras naciones como muchas latinoamericanas, Estados Unidos positiviza tarde este derecho. Otros Estados, con sus propias circunstancias y legislaciones, también se prepararán para asimilar los contenidos de libertad y justicia. El poeta mira la historia de la humanidad como una epifanía que ofrece la posibilidad de advertir a sus lectores el futuro prometedor reservado en la tierra: "I see Freedom, completely arm'd and victorious and very haughty, with Law on one side and Peace on the other,/ A stupendous trio all issuing forth against the idea of caste; / What historic denouements are these we so rapidly approach?” (Whitman, 2003d: 544). 
En la prosopopeya, la Libertad se encuentra armada, altiva y satisfecha de salir victoriosa. De un lado tiene la Ley como espada o lanza y, del otro, ostenta la Paz como escudo. No obstante, permanece la pregunta sobre el porvenir que se encuentra garantizado con la triada. Pero ¿por qué la libertad está armada? Quizás sea porque en el imaginario literario y político ella se opone o resiste a los impulsos externos: debe estar preparada para la invasión. Del mismo modo como lo observa Isaiah Berlin, unos de los filósofos que más ha pensado la libertad en la modernidad (2001b: 96), "la esencia del concepto de libertad, tanto en sentido "positivo» como «negativo» es oponerse a alguien o a algo -a los que se meten en mi terreno, o a los que afirman su autoridad sobre mí; o a obsesiones, miedos, neurosis y fuerzas irracionales-intrusos y déspotas de uno u otro tipo". Empero, el Whitman de la libertad positiva o el poeta constructor de naciones, no se detiene hasta vislumbrar el designio de vida pública. No hay una cita más elocuente que pudiera describir la figura de Whitman en Isahia Berlin (2001c: 64), sin hacer necesariamente referencia a el poeta, como ésta: "Y, como en el caso del yo "positivo» libre, esta entidad puede hincharse hasta convertirse en una entidad supra-personal -un Estado, una clase, una nación, la marcha misma de la historia, considerada como sujeto de atributos más «real» que el yo empírico-”. Ese yo es completamente whitmaniano.

En el pensamiento de Whitman, que preconiza el liberalismo igualitario, el triunfo de la libertad es sólo la antesala donde la justicia puede darse. Además de esto, para que una sociedad viva justamente, es necesario que exista la igualdad entre sus miembros, independientemente de sus condiciones, aptitudes o dones. Esto coincidirá mucho tiempo después con A Theory of Justice de John Rawls, publicada en 1971. En una de sus reflexiones poéticas, Whitman (2003e: 124) afirma: "Of Equality -as if it harm'd me, giving others the same chances and rights as myselfas if it were not indispensable to my own rights that others possess the same". Ahora bien, por su parte, John Rawls (1971a: 53), más de un siglo después, afirma en su primer principio de justicia: "First: each person is to have an equal right to the most extensive scheme of equal basic liberties compatible with a similar scheme of liberties for others". Este principio genérico se concatena con un segundo principio, que, para el filósofo de Harvard, se bifurca en un binomio, es decir, lo que se conoce como el principio de la diferencia y el principio de justa igualdad de oportunidades: "Second: social and economic inequalities are to be arranged so that they are both (a) reasonably expected to be to everyone's advantage, and (b) attached to positions and offices open to all" (Rawls, 1971b: 53).

Pareciera que la reflexión de Whitman se adelanta en ciertos puntos a la de Rawls. Cabe decir que el poeta aún contempla una definición liberal cercana al harm principle de John Stuart Mill, ${ }^{10}$ sin embargo, al decir que se conceden a los demás las mismas oportunidades y derechos que él posee, ya se orienta hacia el primer principio rawlsiano. Por su parte, el principio de diferencia, entendido como el deber de brindar el mayor beneficio posible a los miembros menos aventajados de la sociedad, se encuentra implícito en gran parte de su obra poética. El canto que eleva se identifica con 
el pueblo, tomando especial interés en empatizar con los marginados y con quienes la estatalidad no categoriza como ciudadanos plenos. Walt Whitman (2003f: 30) se encarga de sublimar el reclamo y la pena.

I will leave all and come and make the hymns of you,

None has understood you, but I understand you,

None has done justice to you, you have not done justice to yourself, None but has found you imperfect, I only find no imperfection in you, None but would subordinate you, I only am he who will never consent to subordinate you, I only am he who places over you no master, owner, better, God, beyond what waits intrinsically in yourself.

En la anterior estrofa el poeta se dirige específicamente a ese personaje indeterminado -que bien podría ser un obrero, un campesino, un marinero, un niño o una mujer-, para anunciarle que el himno que funda tiene una sola subjetividad destinataria. La voz lírica no solamente reivindica al marginado, también lo redime: nadie le ha hecho justicia, empezando por él mismo. Más adelante, el poeta exhorta a realizar un examen colectivo, no necesariamente para aventajar al pobre y al oprimido, sino para que todos los ciudadanos se sitúen en una plataforma común. Después de comparecer, la masa se convertirá alegóricamente -cumpliendo con la metáfora organicista- en un solo hombre lleno de empatía e incapaz de negar los defectos y virtudes del ser social:11
You felons on trial in courts, You convicts in prison-cells, you sentenced assassins chain'd and handcuff'd with iron, Who am I too that I am not on trial or in prison?

Me ruthless and devilish as any, that my wrists are not chain'd with iron, or my ankles with iron?

You prostitutes flaunting over the trottoirs or obscene in your rooms,

Who am I that I should call you more obscene than myself?

O culpable! I acknowledge--I expose!

(O admirers, praise not me--compliment not me--you make me wince, I see what you do not--I know what you do not.)

Inside these breast-bones I lie smutch'd and choked,

Beneath this face that appears so impassive hell's tides continually run,

Lusts and wickedness are acceptable to me, I walk with delinquents with passionate love, I feel I am of them--I belong to those convicts and prostitutes myself,

And henceforth I will not deny them--for how can I deny myself?

De acuerdo con Rawls (1971d: 28) "that in justice as fairness the concept of right is prior to that of the good. A just social system defines the scope within which individuals must develop their aims, and it provides a framework of rights and opportunities and the means of satisfaction within and by the use of which these ends may be equitably pursued". Contrariamente para Whitman, el concepto de bien sí es previo al de lo justo. La 
forma de justicia de Whitman es una teoría de la bondad ciudadana. Bajo esta pauta, el poeta está más cercano al liberalismo ético o, en su caso, a un republicanismo perfeccionista: es escéptico ante los procedimientos formales encaminados a alcanzar lo justo. La justicia no puede encapsularse en decisiones: una sentencia expuesta por jueces naturales que nunca dan la cara, pues la delicadeza de lo justo no puede nombrarse con palabras: "Of justice-as If Justice could be anything but the same ample law, expounded by natural judges and saviors,/ As if it might be this thing or that thing, according to decisions" (Whitman, 2003g: 122).

El punto culminante en el pensamiento de Walt Whitman es aquel donde el poeta vislumbra los secretos que Dios tiene reservados para el pueblo americano: una teofanía sobre el poder. "La democracia no podía quedar probada hasta que desplazara los dorados feudalismos del pasado europeo, e hiciera a cada hombre y a cada mujer igualmente independiente. La construcción vertical de las masas por medio de la construcción vertical de grandes individuos-esta era la médula de su libro (...) Walt no había perdido su sentido del poeta como profeta" (Deutsch, 1992d: 125).

Whitman intenta trasplantar la idea de paraíso: edificar un cielo americano, teniendo como materia fundante el barro de los hombres de a pie, ya no más ángeles o demonios miltonianos. "Land tolerating all, accepting all, not for the good alone, all good for thee,/ Land in the realms of God to be a realm unto thyself,/ Under the rule of God to be a rule unto thyself./ (Lo, where arise three peerless stars, / To be thy natal stars my country,
Ensemble, Evolution, Freedom, / Set in the sky of Law.)" (Whitman, 2003h: 488). En esa República, donde surge la ley natural más próxima a Dios, los hombres se integran en una suerte de cuerpo místico renovado y se celebra el sentido panteísta de la vida. Ya no existe la necesidad de jueces que apliquen derecho. Whitman (2003i: 528) describe así a esos nuevos seres que son cófrades de una religión civil: "They shall arise in the States,/ They shall report Nature, laws, physiology, and happiness, / They shall illustrate Democracy and the kosmos, / They shall be alimentive, amative, perceptive,/ They shall be complete women and men, their pose brawny and supple, their drink water, their blood clean and clear".

Finalmente, Whitman considera a la norma como el soporte y producto de un acto creativo: una legislación que se abre sobre cualquier dirección disciplinaria y posibilidad de progreso. Todos somos artistas y dioses; las obras se dan a través de las leyes de una nueva República:

\section{Laws for creations,}

For strong artists and leaders, for fresh broods of teachers and perfect

literats for America, For noble savans and coming musicians. All must have reference to the ensemble of the world, and the compact truth of the world,

There shall be no subject too pronouncedall works shall illustrate the divine law of indirections.

What do you suppose creation is?

What do you suppose will satisfy the soul, except to walk free and own no superior? 
What do you suppose I would intimate to you in a hundred ways, but that man or woman is

as good as God?

And that there is no God any more divine than Yourself?

And that that is what the oldest and newest myths finally mean?

And that you or any one must approach creations through such laws? (Whitman, 2003j: 351 y ss).

\section{Darío: cuando el juez mueve la balanza}

La justicia es un tema poético. Inclusive aquellos poetas que evaden el asunto político participan de un ejercicio ético al omitir el tema. Desde las dos directrices establecidas al finalizar el Libro II de La República de Platón para poetizar adecuadamente y conocer el significado correcto de los mensajes divinos, se ha intentado desechar en Occidente cualquier percepción equívoca en el código lingüístico. Por esta razón, para los antiguos, debe quedar claro que la divinidad no es causa de todo, sino de lo bueno -primera directriz- y como cuestiona afirmativamente Sócrates: hay que partir invariablemente de la verdad -segunda directriz-. El diálogo platónico lo dice así: "Entonces-proseguí-, ¿coincides en que la segunda de acuerdo con lo cual se debe hablar y componer poesía sobre los dioses es ésta: que no son magos que se anden transformándose a sí mismos y extraviándonos con mentiras ni de palabra ni de hecho? -Coincido con ello" (Platón, 2009: 259).
Poco han sido acatadas estas directrices en el devenir literario. Inclusive fueron desechadas y se contravinieron por muchos poetas. Uno de ellos fue Rubén Darío (1867-1916) quien, siguiendo el modelo de los Siglos de Oro, escribió versiones personalísimas de los rasgos de los dioses grecolatinos y sus mitos. Más allá de su época madura, donde el modernismo refulge entre cisnes y alejandrinos, es la inquietud del joven Darío -del muchacho que no rebasa los dieciocho años-, la que más se orienta hacia los versos sobre la justicia. Pese a su corta edad, la visión que posee no es ingenua ${ }^{12} \mathrm{ni}$ pretende contribuir a la personificación de la mujer virgen y hermosa del típico locus de la dama de la justicia. En Epístolas y poemas (1885) se lanza sin concesiones contra las consecuencias del aparato económico de una sociedad industrial y burguesa. Esta nueva circunstancia de capitalismo omnímodo sofoca a la musa y pone en apuros la vida de los poetas, quienes no logran incorporarse del todo a la lógica lucrativa de las mercancías y los servicios. Como afirma Ángel Rama (1985a: 17), "Cuando Darío ingresa a la literatura, el liberalismo se ha impuesto en tierras americanas y su funcionamiento en el plano literario establece esta única ley de oro ‘Sé tú mismo’ (...) Para ella no sólo estará en el afán terco de originalidad, sino en las formas literarias que entran en una vertiginosa elaboración personal". En este contexto, hay que leer Ecce homo, poema que además de hacer un recorrido universal sobre entes como la naturaleza, la noche, la selva; trata el tema de la justicia de la siguiente manera:

Ven acá, sociedad, quiero mirarte; voy a descuartizarte.

Jugando a cara o cruz con la Justicia, 
siendo arca de maldad aquel que juzga, levanta a la malicia

y a la honradez sojuzga.

(Juez venal, no es desdoro

que se incline de un lado la balanza

cuando llegue a inclinarse a peso de oro)

Está bien, rellenémonos la panza. (Darío, 2011c: 159)

El poeta se expresa de un modo singular; hace énfasis en el personaje del juez, quien es calificado de «venal» por su accionar con la balanza. La avaricia, llevada a una frivolidad penosa, presenta al cohecho como rutina cotidiana. No hay reparo en que se levante victoriosa la malicia y la honradez quede sojuzgada: la justicia se mercantiliza y con ello la sociedad queda reducida a una multitud de corruptos que saben cómo usar el «peso de oro». La ironía después se hace patente con la caricaturización de la gordura burguesa que se acumula en el sistema. Darío exhorta a ver a la sociedad de frente, reconocerla y reconocerse en ella. Hay que «descuartizarla»: regenerar las piezas. De este modo, existe la esperanza de recomponer los órganos estatales para armonizar los intereses individuales en beneficio del interés general. Visto de un modo político, lo que sugiere el poeta nicaragüense es refundar el pacto social, hacer un consenso superpuesto para aquilatar directrices y principios de justicia.

Cabe señalar que el poeta escribe desde su tiempo, la justicia es algo que se ejerce desde el ahora hacia el pasado, con pretensiones calificadoras. Aunque siempre se tenga un horizonte moral y una explicación histórica de los acontecimientos como apunta en retórica el género forense, los tiempos a veces dialogan e incluso se traslapan. En su poema "El porvenir", con nítidos rasgos whitmanianos, el Presente epagógico declara a la divinidad que: "Del pasado obelisco y la coluna, (sic)/ la estatua del deber, Señor, he hecho;/y del trono del rey, sacra tribuna/ de la ley, la justicia y el derecho" (Darío, 2011d: 137,138).

Con este fragmento se describen los cambios en las visiones del locus de justicia. El obelisco y la columna simbolizan el pasado de la fuerza, donde la piedra se usa para reclamar el derecho autotutelar: aquí la respuesta visceral y apasionada es fuente de decisión legítima. Se trata de una referencia a la venganza privada, remontándose a la majestuosidad del inicio civilizatorio donde los procesos indagatorios y la administración de las penas estaban trastocadas por el pathos; la justicia contenía ese halo místico y solemne que la hacían un fenómeno de fuerza. Sólo aquellos dotados con la prerrogativa divina interpretaban las directrices que los dioses establecían para distinguir la verdad de la mentira y fijar así la historia oficial. En un punto, se cinceló esa «estatua del deber».

La imagen esculpida de la Themis griega o la Justitia romana se modificó con nuevos valores: la venda que cubre sus ojos fue identificada con la imparcialidad, la balanza con el instrumento para mesurar la carga de las pruebas y la espada con el poder coercitivo que surge del Estado (Narváez, 2010: 113-122). ${ }^{13}$ Además, en el poema citado, el Presente no tiene problemas en relatar los favores divinos, lo que ha sabido transformar y materializar en auxilio de los hombres. Así, en una evolución alegórica de las formas de gobierno, el paso de la monarquía a la república supone un 
avance moral que ayuda a garantizar la legalidad. $\mathrm{El}$ «trono del rey» que abreva de una naturaleza litúrgica, absoluta y perpetua, se fragmenta. Cada una de las piezas que lo conforman son explicadas dentro de un campo de acción que distingue con precisión los asuntos estatales y los asuntos clericales, los asuntos privados y públicos, el derecho y la costumbre, la jurisdicción y la arbitrariedad, hasta que todas estas dicotomías desaten la dura malla de potestades y fueros del antiguo régimen.

El temperamento político del joven Darío defiende la ciudad letrada, pues ejerce como un ciudadano tributario de las ideas liberales, en un escenario donde "los poetas se transformarán en los servidores, custodios, de los valores siempre vagos y mal definidos-el ideal y la belleza-, agrupándose en una suerte de cofradía que se autoabastece y dentro de la cual se fabrican, guardan y trasmiten algunos productos de elaboración tan compleja como los artefactos industriales que comienzan a llegar desde Europa” (Rama, 1985b: 47). Darío está convencido de las ventajas del liberalismo republicano. Sin embargo, las costumbres y vicios del antiguo régimen deben ser depurados para que florezcan los valores de la democracia y la igualdad sustancial. ${ }^{14}$ El poeta, amante de la cultura francesa, además de leer en su juventud a los poetas parnasianos y malditos, indudablemente se acercó también al pensamiento político de esa tradición, es decir, a la rica vía ilustrada y después romántica de la Revolución francesa. De tal suerte que hay que revisar hasta donde llega el "galicismo mental» que le reprocha Juan Valera ${ }^{15}$. En realidad, es un galicismo que afianza su casticismo, como apunta Raimundo Lida (2008a: 35): “Nada es demasiado simple en
Rubén. Su galicismo evidente y múltiple, no es simple galicismo. Trastornar gloriosamente el equilibrio idiomático anterior haciendo afluir a una ancha tradición hispánica, esencias espirituales y verbales, 'no sólo de las rosas de París' sino de todas partes".

El proyecto dariano nunca consistió en afrancesar a la América Latina, sino defender los valores espirituales de un modo hispánico propio de las regiones americanas, a la par de disfrutar del progreso industrial que, en algunos casos, llevaba agridulces claroscuros. "El progreso económico benefició especialmente a la emprendedora burguesía que comienza a cumplir en América la labor que decenios antes había llevado a cabo la europea, aunque cumple su misión histórica en una conflictual situación de dependencia. Las ventajas que su acción acarrea a la vida intelectual fueron vistas por Darío” (Rama, 1985c: 32). Por lo que respecta a la lengua, su posición es panhispánica, pues "No hay por qué condenar los programas de independencia idiomática y cultural, si su meta es de ampliación y enriquecimiento, beneficios para el español de todas partes. El mismo Rubén no se propone otra cosa" (Lida, 2008b: 47). Por otro lado, no hay que olvidar que en su etapa de madurez “exalta y defiende los valores hispánicos contra el peligro de la potencia de los Estados Unidos que bajo la presidencia del presidente Teodoro Roosevelt, había implementado la política del big stick (el gran garrote), actitud que observamos en el 'Prefacio' de Cantos de vida y esperanza, los cisnes y otros poemas donde exclama: 'Mañana podemos ser yanquis y es lo más probable"” (Palacios Vivas, 2007: 17). 
No obstante, regresemos al punto de inicio: el joven Darío que escribe sobre la justicia ${ }^{16}$. En la mayoría de las ediciones que reúnen la poesía completa de Rubén Darío, el punto de partido es Epístolas y poemas (Primeras notas) de 1885, pero hay un pequeño corpus que constituyen sus poesías adolecentes. Ernesto Mejía Sánchez apunta que:

durantesuúltima permanencia en Guatemala, entre abril y noviembre de 1915, Darío tuvo en sus manos el original de sus precoces Poesías de Adolecente (1879-1882); él emocionado, lo reconoció como suyo, antecedente de sus Primeras notas, pero no dijo palabra sobre una posible o futura publicación. Antes bien, cuando se lo ofrecieron en obsequio de inmediato quiso destinarlo a su amigo Archer M. Huntington (...) Darío no hizo ningún movimiento para recuperar ese original primogénito. (Darío, 2011e: xivi).

Como poeta consagrado y figura legendaria de la poesía de nuestra lengua, es comprensible que Rubén Darío buscara enterrar sus primeros balbuceos líricos, todavía muy influenciados del romanticismo y sus maestros. Es probable que en ese libro apareciera un texto curioso que manifiesta elocuentemente la idea de justicia del muchacho con aspiraciones poéticas. Se trata de "Un pleito", 17 considerado una paráfrasis en español o la traducción versificada de la fábula "Le Fromage" del francés Antoine Houdart de La Motte (1672-1731).

El poema octasilábico narra los hechos con un registro lúdico y romancea con sátira. Dos gatos de Angola, hábiles ladrones, llegan a un mesón para repartirse el botín: un rico queso de bola. Después se establece la litis: "Como equitativamente/ no lo pudieron partir,/ acordaron recurrir/ a un mono muy competente;/ mono de mucha conciencia/ y que gran fama tenía,/ porque el animal sabía/ toda la Jurisprudencia" (antologado en Calderón, 2000a: 58 y ss). Como se observa, ambos personajes acuden buscando equidad. Se entiende que el juez, mono sabio, por sus conocimientos de «Jurisprudencia» puede resolver el problema. Aquí, en un primer momento, se recalca la importancia para administrar justicia formal: acatar el contenido de las normas sin considerar una práctica de virtud judicial, obviando aspectos morales y políticos. En el poema, los felinos acuden con quien tiene competencia.

Posteriormente los gatos entregan el queso al mono de forma consensuada y aceptan su arbitraje. Quizás sea más propio desde la técnica jurídica hablar de árbitro y no de juez, puesto que no interviene una autoridad con imperium. Expresamente ambas partes solicitan la partición del alimento en «mitades de igual peso e idénticas proporciones». Darío cuenta, como espectador lejano que sólo relata los acontecimientos, que: "Aquel mono inteligente/ observa el queso de bola,/ mientras menea la cola/ muy filosóficamente./ -Recurrís a mi experiencia/ y el favor debo pagaros,/ amigos, con demostraros/ que soy mono de conciencia;/ voy a dividir el queso,/ y, por hacerlo mejor,/ rectificaré el error,/ si hubiere, con este peso-" (Calderón, 2000b: 58 y ss). Se puede presumir que el mono es un juez-filósofo no sólo porque «menea la cola» meditabundo, sino porque se plantea como subjetividad prudente: tiene experiencia y es consciente de los hechos. 
Entre tanto, describe el procedimiento para dar certeza a las partes. El mono saca una balanza para evitar inexactitudes, mientras los felinos toman asiento y se relamen los bigotes. Valiéndose de un cuchillo salomónico, el juez parte la bola y coloca un trozo en cada platillo: usa una fórmula de peso empírica y milenaria.

\section{pero no estuvo acertado \\ al hacer las particiones, y tras dos oscilaciones \\ se inclinó el peso hacia un lado.}

Para conseguir mejor

la proporción que buscaba

en los trozos que pesaba,

le dió un mordisco al mayor;

pero como fué el bocado

mayor que la diferencia

que había, en la otra experiencia

se vió el mismo resultado,

y así, queriendo encontrar

la equidad que apetecía, los dos trozos se comía sin poderlos nivelar" (Calderón, 2000c: 58 y ss).

Al final se suscitan errores en el procedimiento que teóricamente parecía racional y viable. De algún modo, considerando una lectura extensiva al campo filosófico, el mono se encuentra bajo un déficit epistémico que le impide mirar el asunto con plena objetividad. Al parecer, la justicia como imparcialidad resulta una hipótesis irrealizable en la otra América: nadie puede actuar tras un velo de ignorancia como lo plantea Rawls. Precisamente la lucha, anticipada por el reclamo, es lo que prosigue en el poema burlesco. Uno de los gatos, al ver cómo un tercero come su botín, reclama el método fallido. A su vez, el otro gato apoya la moción. Hasta que "Dice el otro con furor,/ mientras la cola menea:/ -Dáme una parte, ya sea/ la mayor o la menor;" (Calderón, 2000d: 58 y ss) así, los litigantes, después de ver la onerosidad del procedimiento, deciden salvar algún beneficio sin obtener migajas de imparcialidad. No será sino hasta la tercera parte del poema cuando se dé conclusión al pleito:

El juez habla de este modo a los pobres litigantes:

-Hijos, la Justicia es antes que nosotros y que todo.

Y otra vez vuelve a pesar y otra vez vuelve a morder; los gatos a padecer y la balanza a oscilar.

Y el mono, muy satisfecho de su honrada profesión, muestra su disposición para ejercer el Derecho.

Y cuando del queso aquél quedan tan pocos pedazos que apenas mueven los brazos de la balanza en el fiel, el mono se guarda el queso y a los gatos les responde: -Esto, a mí me corresponde 
por los gastos del proceso (Calderón, 2000e: 58 y ss).

Como se muestra, hay una amplificación trágico-cómica del mono como administrador de la justicia, cuya guía debe ser prioritaria y previa a cualquier interés: algo que es «antes que nosotros y que todo». La «Justicia»-en mayúscula como Whitman- es algo que se sufre y no deja de «oscilar» con incertidumbre para los ciudadanos en los juzgados de la América Latina. Aparentemente el mono a lo largo del poema se muestra imparcialmente como experto letrado, orgulloso de su "profesión», quien ejerce el derecho desde dos aristas: la normativa y la axiológica, apareciendo esa tensión moderna -planteada por Kant- entre la justicia del jurista y la justicia del filósofo¹8.

La resolución final, más allá del gesto satírico de tomar «los gastos del proceso», se puede leer en dos sentidos: 1) el mono, a través de su posición de juzgador virtuoso, se desentiende de las reglas del procedimiento y busca justicia retributiva por medio de una medida discrecional. El mono detenta los intereses colectivos y corrige la acción delictiva aplicando la epiqueya; o, en su caso, 2) el juez en realidad es un ser corrupto y persigue su provecho. En esta opción quedaría impresa la crítica mordaz que hace el joven Darío a un sistema judicial que únicamente responde a intereses mezquinos. Por más formalidad aplicable, la exigencia de justicia se extravía entre libelos y abusos autoritarios. Sin saber si fluye más la tragedia o la comedia, la búsqueda de la justicia sería una fina utopía anticipada por el fracaso: una inversión infructuosa que se revuelve con sus propias piezas y sin final feliz. Por esta razón, rumbo al final de su vida, Darío (2011f: 422) invierte los valores tópicos atendiendo a una interpretación personal del derecho natural en uno de sus "Augurios”: " $; O h$ paloma!/ Dame tu profundo encanto/ de saber arrullar, y tu lascivia/ en campo tornasol; y en campo/ de luz tu prodigioso/ ardor en el divino acto./ (Y dame la justicia en la naturaleza,/ pues, en este caso,/ tú serás la perversa y el chivo será el casto.

\section{El dictado de la justicia en las dos Américas}

Todavía en muchos tribunales los operadores dictan sus resoluciones teniendo presente una justicia procedimental y abstracta. Sin embargo, esta espectralidad formalista se disipa cuando se hace un acercamiento material y concreto a los efectos de cada resolución o cuando una práctica normativa del sistema es desarmada por la exposición al canon occidental de los human rights y que en América Latina se entiende más con la tradición iberoamericana de los derechos humanos. ${ }^{19} \mathrm{En}$ nuestra realidad, surge la pesadumbre expresada en el famoso ensayo "Nuestra América" de Martí al hablar de las «repúblicas dolorosas». Es decir: ¿por qué no logran convivir equitativamente las justicias enunciadas en las dos Américas?

Los esfuerzos teórico-poéticos en Whitman y Darío quieren dar cuenta de distintas realidades dentro de las sociedades decimonónicas de las dos Américas. Los escenarios se tensan debido a las condiciones culturales que codifican la lengua. Entre lo más significativo, hay que reconocer en cualquier teoría de la justicia sensata, que la hegemonía económica termina determinando las relaciones continentales. Darío tuvo una relación 
poética traspasada por el poder del liberalismo económico y en el canto whitmaniano se escuchan notas imperialistas a través de una fe ciega en el progreso. Mientras que el estadounidense mantiene un determinismo místico en la palabra justice; Darío expone las contradicciones de esa palabra extranjera al importarse en condiciones paradójicas. Whitman solicita en sus poemas el retorno de un ideal de Justicia para afianzar un fin planetario, a diferencia de Darío, quien entiende que ese ideal se disipa en las manos de los hombres. Sin embargo, ambas visiones están inmersas en una dialéctica histórica y ambos poetas creen en el poder civilizatorio de la ley. La justicia poética como dictum de los poetas abre los problemas profundos de inequidad en la región o, de algún modo, los recurrentes desfases entre la teoría y la práctica.

\section{Referencias citadas}

Acereda, A., "Las otras miradas de Rubén Darío a Estados Unidos" en Oviedo Pérez, R. (ed) (2014): Rubén Darío en su laberinto, Madrid, Verbum editorial.

Berlin, I. (2001a): Dos conceptos de libertad, Madrid, Alianza.

Berlin, I. (2001b): Dos conceptos de libertad, Madrid, Alianza.

Berlin, I. (2001c): Dos conceptos de libertad, Madrid, Alianza.

Calderón, J. (2000a) Rubén Darío para niños, Madrid, Ediciones de la Torre.
Calderón, J. (2000b) Rubén Darío para niños, Madrid, Ediciones de la Torre.

Calderón, J. (2000c) Rubén Darío para niños, Madrid, Ediciones de la Torre.

Calderón, J. (2000d) Rubén Darío para niños, Madrid, Ediciones de la Torre.

Calderón, J. (2000e) Rubén Darío para niños, Madrid, Ediciones de la Torre.

Darío, R. (2015a): La vida de Rubén Darío escrita por él mismo, México, FCE.

Darío, R. (2015b): La vida de Rubén Darío escrita por él mismo, México, FCE.

Darío, R. (2000): Los limos más hondos y secretos. (Poemas ausentes en sus Poesías completas), $2^{\mathrm{a}}$ ed., trad. de José Jirón Terán y Jorge Eduardo Arellano, Managua, Gurdián de Impresiones.

Darío, R. (2011a): Poesía, ed. Ernesto Mejía Sánchez, Managua, Hispamer.

Darío, R. (2011b): Poesía, ed. Ernesto Mejía Sánchez, Managua, Hispamer.

Darío, R. (2011c): Poesía, ed. Ernesto Mejía Sánchez, Managua, Hispamer.

Darío, R. (2011d): Poesía, ed. Ernesto Mejía Sánchez, Managua, Hispamer.

Darío, R. (2011e): Poesía, ed. Ernesto Mejía Sánchez, Managua, Hispamer. 
Darío, R. (2011f): Poesía, ed. Ernesto Mejía Sánchez, Managua, Hispamer.

De Asís Fernández, F. (1980), Poesía política nicaragüense, México, UNAM.

De la Torre Rangel, J. (2014): Tradición Iberoamérica de Derechos Humanos, México, Porrúa-

Escuela Libre de Derecho.

Deutsch, B. (1992a): Walt Whitman: constructor para América, trad. Rodolfo Usigli, México, Séneca.

Deutsch, B. (1992b): Walt Whitman: constructor para América, trad. Rodolfo Usigli, México, Séneca.

Deutsch, B. (1992c): Walt Whitman: constructor para América, trad. Rodolfo Usigli, México, editorial Séneca.

Deutsch, B. (1992d): Walt Whitman: constructor para América, trad. Rodolfo Usigli, México, editorial Séneca.

González García, José M. (2016): La mirada de la Justicia, Madrid, AntiMachado Libros.

Kant, I. (2012): Sobre la paz perpetua, trad. Kimana Zulueta, Madrid, Akal.

Lida, R. (2008a): “Notas al casticismo de Rubén” en De la literatura hispánica moderna, México, El Colegio de México.

Lida, R. (2008b): “Notas al casticismo de Rubén” en De la literatura hispánica moderna, México, El Colegio de México.

Martínez, J. (2000a): Rubén Darío. Addenda, Palencia, Calamo.
Martínez, J. (2000b): Rubén Darío. Addenda, Palencia, Calamo.

Mill, J. (1984): El utilitarismo, trad. Esperanza Guisán, Madrid, Alianza.

Mill, J. (2006): Ensayo sobre la libertad, Mestas ediciones, Madrid.

Narváez, J. (2010): Cultura jurídica: ideas e imágenes, Porrúa, 2010.

Nussbaum, M. (1997): Justicia poética: la imaginación literaria y la vida pública, trad. Carlos Gardini, Barcelona, editorial Andrés Bello.

Palacios Vivas, N. (2007): Nuevos asedios a Rubén Darío, Managua, ediciones 400 elefantes.

Paz, O. (1997): La casa de la presencia: poesía e historia. Obras completas, México, FCE.

Platón (2009): La República, trad. Sánchez-Elvira, Torres y Romero, Madrid, Akal.

Rama, A. (1985a): Rubén Darío y el modernismo, Carcas, Alfadil ediciones.

Rama, A. (1985b): Rubén Darío y el modernismo, Carcas, Alfadil ediciones.

Rama, A. (1985c): Rubén Darío y el modernismo, Carcas, Alfadil ediciones.

Rawls, J. (1971a): A Theory of Justice, Cambridge, Harvard University Press. 
Rawls, J. (1971b): A Theory of Justice, Cambridge, Harvard University Press.

Rawls, J. (1971c): A Theory of Justice, Cambridge, Harvard University Press.

Rawls, J. (1971d): A Theory of Justice, Cambridge, Harvard University Press.

Rawls, J. (1971e): A Theory of Justice, Cambridge, Harvard University Press.

Whitman, W. (2003a): Poesía completa (edición bilingüe), trad. Manuel Villar Raso, 9 ed., Barcelona, ediciones 29.

Whitman, W. (2003b): Poesía completa (edición bilingüe), trad. Manuel Villar Raso, 9 ed., Barcelona, ediciones 29.

Whitman, W. (2003c): Poesía completa (edición bilingüe), trad. Manuel Villar Raso, 9 ed., Barcelona, ediciones 29.

Whitman, W. (2003d): Poesía completa (edición bilingüe), trad. Manuel Villar Raso, 9 ed., Barcelona, ediciones 29.

Whitman, W. (2003e): Poesía completa (edición bilingüe), trad. Manuel Villar Raso, 9 ed., Barcelona, ediciones 29.

Whitman, W. (2003f): Poesía completa (edición bilingüe), trad. Manuel Villar Raso, 9 ed., Barcelona, ediciones 29 .

Whitman, W. (2003g): Poesía completa (edición bi- lingüe), trad. Manuel Villar Raso, 9 ed., Barcelona, ediciones 29.

Whitman, W. (2003h): Poesía completa (edición bilingüe), trad. Manuel Villar Raso, 9 ed., Barcelona, ediciones 29.

Whitman, W. (2003i): Poesía completa (edición bilingüe), trad. Manuel Villar Raso, 9 ed., Barcelona, ediciones 29 .

Whitman, W. (2003j): Poesía completa (edición bilingüe), trad. Manuel Villar Raso, 9 ed., Barcelona, ediciones 29.

Whitman, W. (1991): Hojas de hierba, trad. Jorge Luis Borges, Barcelona, Lumen.

\section{Notas}

1Buena parte de las reflexiones del presente ensayo, con algunas modificaciones y actualizaciones epistemológicas del autor, fueron producto de los cursos impartidos por René González de la Vega en el Posgrado de Derecho en la UNAM, quien siempre confió en las relaciones entre DyL en el marco de la teoría de la justicia y la filosofía moral. Agradezco enormemente sus observaciones y magisterio.

2Para Nussbaum, (1997: 163) "la justicia poética necesita equipararse de gran cantidad de atributos no literarios: conocimiento técnico legal, conocimiento de la historia y de los precedentes, atención a la debida imparcialidad".

${ }^{3}$ El poema se publicó en febrero de 1857, en El Correo de Ultramar. Desde el inicio se comenta que la Amé- 
rica del norte es "Rica, potente, activa y venturosa". Esta América que alcanzó su independencia y prosperidad económica se opone a la América del Sud, que es la América Latina. Se considera que junto con la referencia al poemay los textos del chileno Francisco Bilbao, se usó por primeras veces la expresión "América Latina”. La estrofa del poema dice: "Mas aislados se encuentran, desunidos,/ esos pueblos nacidos para aliarse:/ La unión es su deber,/ su ley amarse:/ Igual origen tienen y misión;/ la raza de la América latina,/ al frente tiene la sajona raza,/ enemiga mortal que ya amenaza/ su libertad destruir y su pendón.”

4La primera edición se publica en 1888 en Valparaíso por la Imprenta y Litografía Excélsior. Dos años después aparece la edición guatemalteca. Sobre los "Medallones dice Martínez (2000a: 185) que "con los 'Medallones' cabría la sospecha-y sólo la sospecha- de que fueron incorporados a esta edición a última hora; primero, porque Darío estaba pensando en ellos como poemas para otro libro distinto, titulado precisamente Medallones".

${ }^{5}$ Además de este poema, Whitman aparece también en las "Palabras liminares" de Prosas profanas. Hay que advertir que el estilo whitmaniano, desde un punto de vista épico y político, es empleado por Darío en el Canto a la Argentina (1914).

${ }^{6}$ Por esta razón, en la lógica editorial y de tirajes de libros, Octavio Paz (1997: 546) ve en estos poetas clásicos de lectura: "Aunque Baudelaire murió hace más de un siglo, es nuestro contemporáneo. Su suerte fue después la de Verlaine, Rimbaud y Mallarmé: los libros de estos poetas están en todas las bibliotecas y son leídos por miles y miles de personas civilizadas (...) Las historias de las ediciones de Baudelaire y de
Whitman han sido las de todos los poetas modernos en todas las lenguas. Las primeras ediciones son casi siempre confidenciales, pero, por un proceso al mismo tiempo lento y seguro, sus libros alcanzan, al cabo de los años, grandes tirajes y vastas audiencias”.

${ }^{7}$ Esto queda patente en las acciones del individuo que desembocan en la originalidad: "La espontaneidad no entra en el ideal de la mayoría de los reformadores morales y sociales; por el contrario, la consideran más bien con recelo, como un obstáculo molesto y quizás rebelde frente a la aceptación general (...) la individualidad de poder y desenvolvimiento, que para esto precisa de dos requisitos: «libertad y variedad de situaciones». Su unión produce «el vigor individual y la diversidad múltiple», que se funden en la originalidad" (Mill, 2006: 98, 99).

8Una de las traducciones más celebradas de Walt Whitman es la que hace Jorge Luis Borges: Whitman (1991).

9En el constitucionalismo estadounidense fue la Decimotercera Enmienda la que abolió oficialmente la esclavitud en el territorio Estados Unidos de América y, en la mayoría de los estados de la Unión, prohibió la servidumbre involuntaria. La enmienda fue propuesta el 31 de enero de 1865 a las legislaturas de varios estados por parte de la XXXVIII legislatura del Congreso de Estados Unidos.

${ }^{10}$ Considerando el deseo de justicia, John Stuart Mill (1984: 146-147) considera el principio de daño de la siguiente manera: “A mi modo de ver, el sentimiento de justicia es el deseo animal de ahuyentar o vengar un daño o perjuicio hecho a uno mismo o alguien con quien uno simpatiza, que se va agrandando de modo que incluye a todas las personas, a causa de la capa- 
cidad humana de simpatía ampliada y la concepción humana de autointerés inteligente".

${ }^{11}$ A diferencia de Rawls quien, para homogeneizar a los hombres, utiliza la posición original; Whitman crea esta especie de examen a posteriori para "purgar" los conflictos sociales. Así ve Rawls (1971c: 37) la posición original en su teoría de la justicia: "In justice as fairness the role of intuition is limited in several ways. Since the whole question is rather difficult, I shall only make a few comments here the full sense of which will not be clear until later on. The first point is connected with the fact that the principles of justice are those which would be chosen in the original position. They are the outcome of a certain choice situation. Now being rational, the persons in the original position recognize that they should consider the priority of these principles".

${ }^{12}$ Darío empezó a leer desde temprana edad. Así lo recuerda: "En un viejo armario encontré los primeros libros que leyera. Eran un Quijote, las obras de Moratín, Las Mil y una noches, la Biblia, los Oficios de Cicerón, la Corina de Madame Stäel, un tomo de comedias clásicas españolas, y una novela terrorífica, de ya no recuerdo que autor, La Caverna de Strozzi. Extraña y ardua mezcla de cosas para la cabeza de un niño" (Darío, 2015b: 31).

13Para revisar una explicación iconológica de la imagen dela justicia, ver subcapítulo 15. También se recomienda el libro La mirada de la justica. Sobre el elemento de la venda que fue una lucha medieval y renacentista, "La introducción de la venda tuvo dos significados contrapuestos: al principio la venda fue comprendida como injusta precisamente porque negaba la capacidad de la Justicia para verlo todo (...) después la venda o los ojos cerrados de la Justicia se transforman en un símbolo positivo de igualdad de todos los individuos ante la ley” (González García, 2016: 22).

${ }^{14}$ Para Francisco de Asís Fernández, en Nicaragua, políticamente el "proceso que culmina con Darío y con la toma del poder por el liberalismo en 1893, es iniciado en la misma guerra civil y antifilibustera y continuado posteriormente en los 'Treinta Años' de gobiernos conservadores (1867-1893), quienes tomaron el poder, tanto por el resquebrajamiento de las fuerzas liberales en la guerra y su débil participación ideológica en las fuerzas beligerantes, como por la fuerza que significaba una fracción de clase organizada en posesión de la tierra, con el control del comercio y una letra que con sangre entra. Es imprescindible indicar que durante el período de paz de los 'Treinta Años', Nicaragua se vincula al mercado capitalista mundial, a través de la explotación extensiva del café" (De Asís Fernández, 1980: 8).

${ }^{15} \mathrm{~A}$ partir de las dos cartas que Juan Valera dirige a Rubén Daríoy publica en octubre de 1888 en el diario El Imparcial, donde se le reconoce como poeta de talento y se le reprocha su excesiva influencia francesa, en las ediciones subsecuentes de Azul... se suele incluir dichas epístolas como prólogo al libro. "Ningún otro joven autor americano había conseguido honores tan altos de la pluma de don Juan; el único caso semejante había sido el de Rafael Obligado, poseedor también de un ejemplar de Azul... cuyo prestigio superaba entonces al de Rubén. Conseguir una crítica de don Juan Valera suponía 'alcanzar la gloria de un solo golpe' (...). Y de esto era consciente Darío, que desde muy pronto se sirvió de las cartas como credenciales de presentación" (Martínez, 2000b: 179). 
${ }^{16}$ Como sabemos, la crítica especializada considera una posición ambivalente respecto a la valoración del imperialismo norteamericano que el poeta tuvo en vida. Ver: (Acereda, 2014: 153-166).

${ }^{17} \mathrm{El}$ poema, como ya se dijo, no es incluido en la poesía completa de Rubén Darío (2000), por esta razón, no queda clara la autoría y no se descarta una pieza atribuida a él o un poema apócrifo.

18Para Kant (2012: 92) “(el jurista) que ha adoptado como el símbolo la balanza del derecho, además de la espada de la justicia, se sirve comúnmente de la última, no sólo para apartar la influencias externas a la balanza, sino también para el caso de que tenga que poner la espada en el platillo (vae victis) para que no se hunda el mismo, hacia lo que el jurista, que al mismo tiempo no es filósofo, (según la moral) sufra la mayor tentación, pues su deber es solamente aplicar las leyes existentes, pero no investigar si las mismas leyes necesitan alguna mejora”.

${ }^{19}$ Atendiendo a Antonio de la Torre Rangel (2014: 147148), quien valora los esfuerzos jurídicos en clave de derecho natural y uso alternativo del derecho de Vasco de Quiroga y De las Casas, partiendo de las raíces de esta tradición, menciona que "los presupuestos teóricos de nuestra Tradición Iberoamérica de Derechos Humanos, son: primero: parte del pobre, deloprimido, es decir de aquel que padece la injusticia por que ha sido negado en sus derechos; segundo: concibe al ser humano tanto en su aspecto individual como en sus lazos sociales, esto es personal y comunitariamente; $y$ tercero: entiende que entre derechos de unas personas y otras, existe la mediación de la justicia; que la factibilidad de los derechos solo es posible con la justicia" 